\title{
ARTIGO BIBLIOGRÁFICO UMA ANTROPOLOGIA ALÉM DE NATUREZA E CULTURA?
}

Perig Pitrou

\begin{abstract}
INGOLD, Tim \& PALSSON, Gisli (eds.). 2013. Biosocial Becomings. Integrating social and biological anthropology. Cambridge: Cambridge University Press. 286 pp.
\end{abstract}

A Antropologia se estabeleceu como uma disciplina independente ao designar o social como um campo de estudos específico, permitindo que se distanciasse de certas posições retrógradas encontradas nos domínios da antropologia física. Contudo, a dicotomia natureza/cultura em que esta divisão se baseou tem sido objeto de constante crítica ao longo das últimas décadas. Os dois editores de Biosocial becomings, assim como Bruno Latour e Philippe Descola, demonstraram os limites destes conceitos na explicação das práticas e das representações humanas. Agora que esta desconstrução começou, o desafio para nossa disciplina é definir uma antropologia "além de natureza e cultura". Que princípios devem guiar nossa pesquisa? Que metodologias deveriam ser empregadas pelos etnólogos? Que conceitos podem tornar seus resultados inteligíveis? No contexto desse vasto empreendimento de refundar e tornar a desenvolver, o painel organizado por Tim Ingold e Gisli Palsson em 2010, como parte da conferência da EASA e intitulado "Human becomings: beyond the 'biological' and the 'social'", visou formular propostas teóricas, ao mesmo tempo em que começava a explorar novos objetos.

No livro que resultou dessa reflexão coletiva, o projeto de "integrar o social e o biológico" é sintetizado por Ingold (no capítulo 1, "Prospect") e por Palsson (capítulo 12, "Retrospect"), que estabelecem um horizonte teórico para o empreendimento. Quanto às demais partes, sua heterogeneidade apresenta certa ambiguidade. Por um lado, essa diversidade pode ser vista como evidência da riqueza potencial de estudos que procuram entender melhor "devires biossociais" por meio da investigação de uma pletora de fenômenos em todo o mundo. Por outro lado, no entanto, esta multiplicidade levanta 
algumas questões difíceis: que lugar é conferido aos processos biológicos nos estudos etnográficos? Deveriam estes estudos usar dados biomédicos ou, em vez disso, deveriam tentar documentar, por outros meios, concepções não biológicas de seres vivos? Como pode a etnografia das sociedades tradicionais contribuir para o conhecimento sobre a vida? Embora os vários capítulos deste trabalho nem sempre respondam explicitamente a estas indagações, eles ao menos têm a vantagem de delinear as problemáticas para as quais a antropologia da vida deve se voltar, caso deseje se desenvolver.

O trabalho de Ingold há muito tem expressado um desejo de ir além das dicotomias; este é um dos temas principais de The perception of the environment (2000), que propôs estudar os organismos sem desconectá-los abstratamente de seus ambientes. Sua introdução aqui revisita ideias deste texto clássico, enquanto afirma com mais ênfase uma concepção alternativa de biologia em cuja base uma antropologia renovada deveria se desenvolver. Ele começa declarando polemicamente que "o neodarwinismo está morto" (:1), antes de seguir para uma vigorosa crítica da influência negativa desta teoria - a seu ver errônea — sobre as explicações dos fenômenos humanos. Ele rejeita certo tipo de epistemologia naturalista para interpretar a evolução da cultura com base no paradigma darwiniano por meio do estabelecimento de uma analogia entre genes e memes.

Marshall Sahlins tem batalhado, por muitas décadas, contra a sociobiologia, proclamando em alto e bom som a primazia dos determinismos culturais. Esta não é a estratégia de Ingold, que em vez disso busca desmantelar os próprios conceitos da biologia, de modo a transformar o uso que as ciências sociais fazem da biologia sem ficar preso em reducionismos. A crítica de Ingold tem como alvo as noções de evolução e design: "A evolução, a nosso ver, não está na mutação, recombinação, replicação e seleção de características transmissíveis. É muito mais um processo vital. E no coração desse processo está a ontogênese" (:6). O argumento que ele usa em defesa desta tese vem de seu trabalho, de 2013, Making, e consiste em atacar o hilemorfismo, que ele considera o calcanhar de Aquiles do neodarwinismo, porque implica tomar a forma de um organismo como algo predeterminado antes de seu desenvolvimento acontecer. Em relação às noções de genes e memes, ele escreve:

a falácia deste modo de pensar está em supor que a forma miraculosamente precede os processos que a desencadeiam. E a maneira de superar a falácia é simplesmente reverter a ordem, dando primazia ao processo da ontogênese aos fluxos e correntes de material implicados na produção e no crescimento por sobre as formas que emergem com ela $(: 7){ }^{1}$ 
Em contraste, o entendimento de Ingold da evolução procura reconceituar a relação dos organismos com o seu ambiente:

Aquilo que estamos acostumados a pensar como um ambiente pode ser mais bem compreendido como uma zona de interpenetração. No âmbito desta zona, os organismos crescem para tomar a forma que tomam, incorporando as linhas de vida de outros organismos ao fazê-lo. Todo organismo é um local de infestação, ele mesmo um vasto ecossistema (:11).

Ao invés de pensar a evolução em termos de linhagem, o projeto de Ingold é enfatizar a importância das "relações mutuamente condicionantes"; a interpenetração é apenas uma modalidade possível dessas relações, que moldam as formas dos seres que coexistem em um mesmo ambiente.

Estas relações mutuamente condicionantes incluem o que podemos chamar de ontogenética ou sistema de desenvolvimento. As formas de vida, portanto, não são nem genética nem culturalmente pré-configuradas, elas emergem como propriedades da auto-organização dinâmica de sistemas de desenvolvimento (:8).

Contrária à ideia de design, a ênfase de Ingold é nas interações entre seres; assim, seres humanos podem ser pensados "em termos não do que são, mas do que fazem" (:8, grifos do original). Como "a vida é uma tarefa", também descrita como uma "linha de fuga" (ver Deleuze e Guattari), então, aparentemente "formas culturais decorrem do tecer da vida, em atividade conjunta" (:8). Caso isso proceda, devemos

pensar a evolução não como uma mudança pelas linhas de filiação, mas como o desdobramento no desenvolvimento de toda a matriz de relações de cujo âmbito as formas de vida (humanas e não humanas) emergem e são mantidas em posição. Isso exige que pensemos sobre essas formas como não sendo nem genética nem culturalmente configuradas, mas como resultado da auto-organização dinâmica dos sistemas de desenvolvimento (:20). ${ }^{2}$

Ao invés de integrar os fenômenos culturais em um esquema evolucionista clássico, a teoria geral de evolução defendida por Ingold enfatiza a porosidade das fronteiras entre humano e não humano, organismo e ambiente, ao se assumir uma visão (eco) sistêmica, a única visão que permite que se afirme legitimamente que "o domínio do social e o biológico são um só" (:9, grifos do original). Ingold pode declarar, sem descontinuidade, que as dinâmicas em operação no ambiente podem também ser observadas na atividade social porque "A pessoa 
[...] não é tanto uma criatura da sociedade quanto um criador ativo e contínuo dos eus dos seus próprios outros. Na nova linguagem da relacionalidade, os eus pessoais são vistos como 'mutuamente constitutivos'" (:13).

Gisli Palsson, no capítulo final, também analisa as implicações da biologia não darwiniana para a definição de antropologia e para os métodos de investigação etnográfica. Embora Palsson cite Marx, seu argumento - menos filosófico que o de Ingold - leva em conta certos avanços nas ciências naturais; especificamente "uma das descobertas mais impressionantes dos estudos genômicos": "a facilidade com que os genes podem ser transferidos rotineiramente por entre organismos de diferentes tipos" (:240). Aqui também a demonstração busca fazer ver que o modelo evolucionista padrão reduz a complexidade do fenômeno vital e, consequentemente, das construções sociais. Ao dialogar com autores como Lynn Margulis, uma grande colaboradora da teoria endossimbiótica, e Dorion Sagan, Palsson enfatiza que a "zona de interpenetração" discutida por Ingold não é apenas uma metáfora, mas uma relação de fato entre seres. Torna-se cada vez mais difícil falar de indivíduos quando se sabe que, das células eucarióticas aos organismos mais complexos, a maioria das formas de vida resulta de uma associação simbiótica. Isto leva Palsson a afirmar que "Se os humanos são conjuntos ou agregados de formas de vida, resultado de combinações de relações biossociais, então eles não apenas evoluíram conjuntamente com micróbios mais-que-humanos; humanos são micróbios" (:241, grifos do original).

Em meio a tal configuração epistêmica, a questão da escala de análise espacial/temporal se torna central. Depois de uma passagem pela questão do Antropoceno (não estamos distantes da hipótese de Gaia, que Margulis também desenvolveu junto a Lovelock), fica claro que humanos não apenas estão conectados à natureza no nível do infinitamente pequeno: "a natureza, seja no nível das células, organismos, ecossistemas ou do planeta, parece ser tão 'fugaz' quanto a sociedade, minando qualquer tentativa de separar os dois domínios analíticos e teóricos em termos de escalas de tempo diferentes" (:237). Se acrescentarmos a isto a comprovação cada vez maior da importância dos processos epigenéticos (que Palsson examina no capítulo 2), poderemos observar como os conceitos das formas de vida trazidos à luz pelos desenvolvimentos contemporâneos na biologia levaram a se repensarem as bases epistemológicas da antropologia: "As imbricações da vida são tanto verticais quanto horizontais e, além disso, tanto sociais quanto biológicas, como quer que sejam definidos estes termos. À luz disto, a perspectiva dos devires biossociais parece ser um dos caminhos mais promissores na agenda teórica" (:233). Segundo Palsson, a dificuldade então passa a ser evitar as "fronteiras disciplinares" (:230 e páginas seguintes) e o desafio é desenvolver 
"linguagens teóricas alternativas" (:238 e páginas seguintes); a noção de "biossocialidade" de Rabinow e a de "natureza cultura" de Harraway são bons exemplos dessas linguagens teóricas alternativas. Seguindo esta linha, certos conceitos aparentemente neutros devem ser abandonados: "É essencial ir além de termos antropocêntricos como 'competição' e 'cooperação', que caracterizaram a teoria neodarwiniana em diversos campos" (:232-3).

Uma vez as bases dessa agenda tendo sido estabelecidas, devem ser especificados os princípios metodológicos pelos quais a investigação etnográfica pode construir e estudar objetos localizados na interface da natureza com a sociedade. Partindo do suposto de que "os humanos se tornam humanos por meio de relações com outros organismos e espécies em devir e com os ambientes em que estão entranhados" (:244, grifos do original), Palsson prossegue delineando a fertilidade da "etnografia multiespécies" (Kirksey \& Helmreich 2010). A "antropologia dos micróbios" (Benezra, DeStefano \& Gordon 2012), "o devir interconectado da vida em sua forma mais-que-humana", e o projeto de Eduardo Kohn para uma "antropologia da vida" rebatizado de "antropologia além do humano" (Kohn 2013) — aparecem aqui como meios de ir além do antropomorfismo e alcançar as interações entre seres vivos em um contexto de trabalho holístico. Tendo dito isto, a etnografia multiespécies está longe de ser a única forma de documentar os "devires biossociais", como atesta a diversidade das demais contribuições reunidas neste volume.

Eugenia Ramirez-Goicoechea (capítulo 4) e Agustín Fuentes (capítulo 3) exploram as implicações epistêmicas ${ }^{3}$ de noções como "construção de nicho" e "herança múltipla"4 para a antropologia biológica, de modo a enfatizar a importância de se levar em conta a atividade humana nos processos evolucionários. Ramirez-Goicoechea nos lembra como os avanços na epigenética levaram a abandonar um tipo de determinismo unilateral que é expresso algumas vezes na discussão de genes: "A biologia gene-centrada e suas disciplinas correlatas não consideram o organismo (ou qualquer outra unidade) como um agente coformador de seu entorno, mas como um recipiente passivo de forças evolucionárias" (:69). Em contraste, "o conceito de construção de nicho captura esse processo complexo autopoiético de ação na evolução" (:69) e lança nova luz, por exemplo, na socialização de crianças (:71). De forma semelhante, Agustín Fuentes escreve: "na nova abordagem que sugiro aqui, o evoluído, estático, final, se afasta, e o foco passa a ser como estamos evoluindo no passado e no presente" (:46). Bipedismo, estresse, vinculação e cooperação são mencionados como exemplos de fenômenos que os "devires biossociais" podem analisar proficuamente.

Os editores de Biosocial becomings, bem como os autores dos dois capítulos discutidos acima afirmam que suas intenções são integrar os fenô- 
menos culturais nos estudos biológicos das populações humanas. Considero, entretanto, que tal aproximação disciplinar levanta certos problemas metodológicos e deontológicos. Embora se deva concordar em tese com o desejo de aliar tantos elementos quantos forem possíveis de forma a entender os fenômenos humanos em toda a sua profundidade, não devem ser esquecidos os aspectos intrusivos e objetivizantes da coleta de dados biológicos. Como pode um etnógrafo usando observação participante reunir informação para entender processos complexos como os explorados pela epigenética? Dizer que os antropólogos deveriam trabalhar em equipe não resolve o problema - uma divisão do trabalho como essa não correria o risco de reintroduzir o dualismo que deveria ter sido deixado para trás? Embora os autores de Biosocial becomings se empenhem em demonstrar a importância de integrar epistemológica e ontologicamente os campos disciplinares e os conceitos que produzem, poucas indicações são oferecidas de como os antropólogos irão realmente proceder. De um capítulo ao seguinte, não apenas o território coberto muda; o que é mais importante, o lugar dado ao conhecimento biológico pelos diferentes autores varia.

No campo da antropologia médica, as pontes entre as disciplinas foram construídas muito tempo atrás; a tarefa se simplificou pelo fato de que os dados biomédicos e mesmo os bioprodutos (sangue e amostras de DNA, por exemplo) preexistem à investigação antropológica, liberando o etnólogo da responsabilidade de ter que coletar amostras sozinho. É o caso do capítulo de Aglaia Chatjouli sobre a vida das pessoas com talassemia, uma doença monogênica que leva os pacientes a passar por frequentes transfusões de sangue. O trabalho de campo de Chatjouli em centros de transfusão de sangue permite que ela construa uma análise em torno do "papel dinâmico das biociências na natureza (humana) reconfigurante" (:86). Inspirando-se em Ingold, ela explica que tentou "iluminar vidas talassêmicas em termos de pessoas-organismos vivendo em um ambiente" (:88, grifos do original). Ela enfatiza que uma nova definição dos seres vivos advém da imbricação crônica dos processos vitais e tecnológicos: "a encorporação da transfusão [é] o ato mais proeminente e vitalício da mediação biomédica... [é] paradigmático da produção biossocial naturalizada do organismo" (:90). A dimensão biológica da existência humana passa a ser irredutível à genética e "intrinsecamente ligada à ação humana, como processo de desenvolvimento e relacional, constantemente em processo" (:105).

A partir de outro ponto de vista — ou de outro "modo de veridicção", diria Latour - a antropologia pode estudar as controvérsias legais levantadas pela erupção de novos biomateriais no espaço social. Aqui, novamente, os cientistas sociais - tal como os juristas - chegam, por assim dizer, depois da batalha, e os etnólogos não precisam colher eles mesmos os dados que estão sendo 
debatidos. O objetivo é trazer à luz as implicações ontológicas e políticas do argumento legal usado para qualificar objetos que nunca antes existiram na história humana. Gisli Palsson discute, por exemplo, os debates que levaram um juiz nos Estados Unidos a anular as patentes de dois genes humanos, BRCA1 e BRCA2, cujas mutações foram associadas com o câncer de mama (:235). A contribuição de Noa Vaisman ao volume (capítulo 6) se dirige a esta questão ao examinar as implicações de uma decisão pela Suprema Corte da Argentina em um caso envolvendo testes de identidade em amostras de DNA. Durante a ditadura militar dos anos 1970, os filhos de centenas de membros da oposição política foram separados de seus pais e secretamente entregues a outros casais com novos documentos de identidade. Além das emoções que esta prática ainda suscita, problemas complexos são levantados quando o sistema judicial tenta restaurar as identidades e os laços familiares dessas crianças.

No caso discutido por Vaisman, uma família (não biológica) se recusou a permitir que uma amostra de sangue fosse coletada de seu filho Guillermo. Quando Guillermo atingiu a idade adulta, ele também se recusou a ter seu sangue testado - uma boa ilustração da resistência que os humanos podem usar para se opor a explorações biossociológicas deste tipo. Finalmente, a Suprema Corte decidiu usar itens pessoais de Guillermo para extrair "material biológico" o suficiente para chegar a uma decisão. Deixando de lado os problemas deontológicos levantados por esta coleta intrusiva, Vaisman investiga o status ontológico dado pelo sistema legal a esses materiais que, "embora pertencentes ao seu corpo, tinham sido desassociados dele no momento do confisco" (:110). Vaisman, que também se aproxima de Ingold, propõe tratar o humano "como um agrupamento de ambientes-organismos-humanos: um humano cujas fronteiras estão sempre abertas ao mundo e cuja existência está mesclada em seu entorno" (:113). Neste contexto, "o DNA 'coletado' não é na realidade obtido, mas uma extensão do nosso corpo-ser, que existe dentro e através de nosso ambiente" (:114).

Seu estudo das várias concepções de pessoa que emergem da decisão escrita pela Corte a levam a concluir que "O veredito da Suprema Corte parece oscilar entre duas visões do sujeito: o sujeito como produto de elos genéticos e o sujeito como produto de seu mundo social" (:116). Este tipo de decisão será cada vez mais frequente à medida que o poder humano sobre seres vivos crescer, e a antropologia encontrará nestas decisões material em cuja base delineará o modo como o status de pessoas altera profundamente organizações sociais. Isto abre caminho para novos tipos de análises, em que explicações sociológicas precisarão incorporar dados biológicos cujo status (prescritivo, descritivo, de agente) irá variar dependendo de como o conhecimento é construído. 
A questão de como aproximar as disciplinas não é a única a que se dedica este livro. Enquanto os desenvolvimentos que acabo de discutir se apoiam no uso de dados biomédicos, este não é o caso em outros capítulos, que usam o conceito de "biossocial" para tanger a problemática dos seres vivos, os autores se situando na tradição da fenomenologia ingoldiana ou procurando enfatizar a especificidade de certas etnoteorias não ocidentais da vida.

A primeira tendência é exemplificada pelo capítulo "'Bringing wood to life': lines, flows, and materials in a Swazi Sawmill", por Vito Laterza, Bob Forrester e Patience Mususa, que descreve uma serraria na Suazilândia. Os autores recorrem às críticas de Ingold da teoria do ator-rede e da noção de agência para afirmar o valor heurístico dos "emaranhados" para a observação das interações entre os seres e focalizar nos fluxos que ziguezagueiam o mundo, ao invés de fazer distinções dicotômicas. Ao adotar uma perspectiva como esta, aparentemente

qualquer coisa que possa a princípio parecer externa ou separada de um organismo irá, depois de um olhar mais atento, se revelar como imanentemente relacionada com o organismo por alguma linha ambulante que mescla as entidades aparentemente separadas imbricadas por meio da troca osmótica e do sustento mútuo (:167).

Diversas páginas são dedicadas à descrição do trabalho na serraria, de maneira a "sensibilizar a percepção do antropólogo - e do leitor — para o fluxo e o movimento dos devires da vida real" (:189) por meio da conexão da serraria com o ambiente vasto no qual organismos e materiais coexistem. Deixo para o leitor a exploração do caminho seguido aqui, que é acompanhado por fotografias reproduzidas pelos autores. Embora esta abordagem não deixe de ter certo charme intelectual, levanta a questão da contribuição que a etnografia não ocidental pode trazer para o conhecimento da vida. Levando em conta que haja, no cerne do projeto de Ingold, uma tese ontológica do que é a vida, pode-se ponderar se estudar as diferentes concepções humanas de vida ainda será importante. Não se corre o risco de os dados etnográficos, ao retratarem entendimentos êmicos de vida, terminarem por se subordinar a uma concepção universal de élan vital, que os etnólogos então buscariam detectar em diversos ambientes?

Outros capítulos focalizam não na abordagem fenomenológica - de acordo com a qual a "abertura para o mundo" nunca é suficiente para mitigar o risco do solipsismo - mas nas etnoteorias que os métodos clássicos de trabalho de campo trazem à luz; é o caso, por exemplo, do capítulo de Istvan Praet, que retorna à tese central de seu trabalho Animism and the question of life (2013). Baseando-se em sua experiência etnográfica entre os 
Chachi da Amazônia, Praet propõe interpretar o animismo não como uma forma extensiva de atribuir vida a uma variedade de seres, mas, pelo contrário, como a tendência a criar um entendimento restritivo desta qualidade. A originalidade da tese de Praet é a de relacionar a etnoteoria com representações restritivas de humanidade sustentadas por muitos diferentes povos. Como explicou Lévi-Strauss em Raça e história (1967), e como demonstra a tabela que mostra "a ocorrência pelo mundo da humanidade restrita" (:196-8), é comum para grupos considerar a si mesmos os "verdadeiros humanos" e excluir seus vizinhos da esfera da humanidade. De forma semelhante, o sutil argumento de Praet, que eu não tentarei rastrear aqui, mostra que as concepções animistas se apoiam em princípios de oposição que não definem as fronteiras entre vivo e morto no mesmo ponto que a biologia e a cosmologia ocidentais.

Isto não significa que reproduzir os entendimentos de povos não ocidentais deva sempre levar à ênfase em suas divergências em relação aos entendimentos da ciência contemporânea. A discussão de Palsson do uso de nomes nas sociedades do Ártico (Inuit, Yupik, Tsimshian) sublinha convergências possíveis. Ele interpreta o papel dos nomes como a manifestação de uma conceptualização de hereditariedade, mas enfatiza que as semelhanças destacadas não se baseiam em essencialismo. No caso destes grupos,

sua própria forma de teoria epigenética ou de sistemas de desenvolvimento, na realidade, se move para além do essencialismo em direção a relações e processos. Sua noção de socialidade e pessoa, evidenciada em boa parte de suas falas sobre nomes, enfatiza a irrelevância da ideia de autonomia do "biológico" como se entende comumente $(: 36)$.

Em suma, pode-se dizer que as etnoteorias destes grupos chegam por seus próprios meios em um tipo de formalização que não entra em conflito com as descobertas mais recentes da ciência ocidental. Quando os estudos etnográficos buscam validar etnoteorias, o objetivo não é o de estabelecer correspondências ou discordâncias possíveis com teorias científicas, as quais estão sujeitas a mudanças de paradigma. Se desejarmos realmente aceder ao movimento de teorização em operação nestas etnoteorias, é essencial desconstruir o conceito de vida. Palsson enfatiza corretamente que a antropologia, ao invés de repetir mecanicamente expressões que têm se tornado, com o passar do tempo, quase clichês ("a própria vida" de Rose, "a vida nua" de Agamben), deve refinar suas categorias analíticas ao estudar "a vida como tal" (Fassin), sem esquecer a distinção de Canguilhem entre "o vivo" e "o vivido" (:242-3).

Eu iria ainda mais adiante, sugerindo que a "vida" não é um fenômeno unitário e que, se desejamos ser precisos, devemos especificar à qual processo 
vital estamos nos referindo quando falamos de vida: reprodução, crescimento, regeneração, movimento ou relação com o ambiente, para citar apenas alguns exemplos. Além disto, parece-me que a antropologia deve prestar mais atenção à distinção entre o vivo (uma multiplicidade de processos que se manifestam em uma multiplicidade de seres) e a vida, entendida como um conjunto de causas que produzem esses processos. Muitos fatos etnográficos provam que, tanto entre povos ocidentais quanto não ocidentais, a teorização da vida frequentemente consiste em imaginar a vida como uma constituição em andamento; portanto, propus estudar a vida no contexto de uma "pragmática geral" (Pitrou 2015). O desafio, então, passa a ser refletir sobre as diversas formas de conceptualizar esta atividade.

Os dados coletados por Gaetano Mangiameli na aldeia kassena de Paga, em Gana, ajudam a esclarecer esta questão. Embora o contexto analítico de Mangiameli (expresso em termos de fluxos e "turbilhões de organismos" [:149]) deva muito à visão ingoldiana de mundo, há diferenças — e, portanto, complexidades - que tornam clara a singularidade da relação dos Kassena com o mundo. Ao sedimentar um entendimento pragmático de seus bosques sagrados, ele pondera como a qualidade de agência é atribuída a não humanos ("É, portanto, necessário supor que as coisas devem ser descritas em termos do que fazem, ou em termos de como são feitas e refeitas, e até mesmo em termos de como fazem a si mesmas" (:147). Neste contexto, narrativas da criação do mundo - seja por autopoiese ou pela intervenção de um demiurgo - constituem objetos interessantes a serem examinados como concretizações de teorias locais que explicam a organização do que é vivo pela intervenção de agentes não humanos (:151).

Seguindo as mesmas linhas, a descrição de altares (puru) - tipos de montes ordenados gradualmente pelos habitantes de um grupamento ilustra como os processos vitais são representados: "Do mesmo modo que os grupamentos podem crescer, diminuir, e às vezes mesmo desaparecer, o monte pode crescer ou diminuir, dependendo da interseção de condições atmosféricas e tendências demográficas no grupamento" (:153). Ações técnicas têm aqui um papel crucial, já que "o puru é construído diariamente, lentamente, por meio de atos marginais. Basicamente, o puru é um monte de lixo: é o lugar onde, diariamente, as mulheres empilham poeira e lixo quando terminam de varrer" (:153). Mangiameli conclui afirmando que "O puru corporifica a centralidade da vida-em-processo em uma filosofia do devir da África Ocidental" (:153-4).

A expressão "vida-em-processo" certamente dá margem à ambiguidade. Devemos entender que processos técnicos - um grupo heterogêneo de ações feitas pelos humanos - ajudam a visualizar processos vitais, como se 
processos técnicos consistissem, eles mesmos, em uma multiplicidade de ações que modificam os seres vivos de dentro e de fora? Ou, pelo contrário, devemos seguir a interpretação de Ingold, que vê a constituição como um tipo de crescimento, tornando o gesto técnico uma extensão dos processos morfogenéticos mais amplos em operação na transformação de seres vivos? Em minha opinião, como já afirmei alhures (Pitrou 2014), o fato de que processos vitais não possam ser reduzidos à morfogênese me leva a dar mais peso à opinião anterior. Minha posição é a de que essa explicação tem a vantagem de dar conta de uma multiplicidade maior de processos e das causas que diferentes povos podem atribuir a eles. Ao invés de partir de uma concepção universal de vida como movimento, ela abre a investigação para a complexidade de etnoteorias desenvolvidas de forma a tornar inteligível a complexidade da vida.

Não obstante o status que decidamos atribuir à constituição e à técnica, é notável que, apesar de sua diversidade, quase todos os artigos de Biosocial becomings transmitam, mais ou menos explicitamente, a ideia de que o estudo de fenômenos vitais deve privilegiar uma abordagem de inspiração pragmática de forma a mapear as configurações em cujo âmbito agentes humanos e não humanos interagem, se constituem, estabelecem relações mútuas, se formam etc. Podemos pensar aqui nas observações de Palsson a respeito do conceito de "meio" em Canguilhem: "O foco no meio não significa que um organismo vivo desapareceu de vista, destituído de agência: pelo contrário, o organismo é o centro irradiador da atividade pragmática" (:27). De forma semelhante, em seu capítulo "Life-in-the-making: epigenesis, biocultural environments and human becomings", Eugenia Ramirez-Goicoechea enfatiza a importância da "ação-na-relacionalidade" (:70) ${ }^{5}$

A originalidade das posições defendidas pelos editores deste trabalho e a diversidade dos campos explorados por seus colaboradores tornam Biosocial becomings um trabalho crucial para os debates atuais da antropologia. Os problemas epistemológicos e metodológicos que levanta certamente irão revitalizar o pensamento em torno da oposição natureza/cultura e contribuir para o projeto de transformação teórica em andamento em nossa disciplina.

Recebido em 19 de dezembro de 2014

Aprovado em 12 de fevereiro de 2015

Tradução do francês ao inglês de Daniela Ginsburg.

Tradução do inglês ao português de Fernanda Guimarães.

Perig Pitrou é pesquisador do Laboratoire d'Anthropologie Sociale do CNRS e membro do Collège de France, Paris. E-mail: <Perig.pitrou@college-de-france.fr> 


\section{Notas}

${ }^{1}$ Baseando-se em uma tese ontológica semelhante e na mesma rejeição da noção de design, Ingold desenvolve uma abordagem original da atividade técnica, vendo-a como a continuação do movimento vital que dá forma a artefatos. Segundo ele, do ponto de vista da morfogênese, é errado pensar que constituição e crescimento, artefato e organismo sejam opostos.

2 “[A evolução] somente pode ser compreendida topologicamente, como o desdobramento da tapeçaria como um todo - da matriz abrangente de relacionamentos em que as múltiplas formas de vida que chamamos 'cultural' emergem e são mantidas no lugar. No âmbito desta matriz, o devir de todo componente tanto condiciona como é condicionado pelo devir de outros componentes com os quais se relaciona" (:8).

3 "A epigenética é chave para a mudança pós-genômica do determinismo genético para um foco nas redes interacionais de processos genômicos estocásticos em ambientes de desenvolvimento. Esta mudança é fundamental para uma abordagem bio-psico-sociocultural dos devires humanos e para uma demonstração de como a vida está em processo" (:80).

4 "A teoria de construção do nicho sugere que os humanos e seus ambientes são participantes mutuamente interativos no processo evolutivo, por meio da herança ecológica. Diversas teorias de herança propõem que a herança relevante em termos evolutivos pode acontecer em níveis genéticos, epigenéticos, comportamentais e simbólicos" (:53). As análises de "herança múltipla" são baseadas, em especial, nos trabalhos de Jablonka e Lamb publicados em Evolution in four dimensions (2005).

${ }^{5}$ Outras citações: "Células sob estresse podem mobilizar sistemas que remodelam seu DNA, ao ativar e desativar genes (cf. Jablonka \& Lamb 2005:88)" (:28); "Segundo o campo em crescimento da epigenética nutricional, como aponta Landecker (2011:177), a comida entra no corpo e nunca o deixa, porque a comida transforma o organismo tanto quanto o organismo a transforma" (:29-30); “Moss (2003) sugere essa perspectiva pragmática para teorizar a vida para além de códigos e genes; ao invés de genes, ele enfatiza que 'é o organismo vivo, como agente ativo de sua própria ontogenia adaptativa e capacidade evolutiva, que mais uma vez é levado a voltar ao assento do motorista ontológico' (Moss 2003:198)" (:32-3). 


\section{Referências bibliográficas}

BENEZRA, Amber; DE STEFANO, Joseph; GORDON, Jeffrey I. 2012. "Anthropology of microbes". Proceedings of the National Academy of Sciences, 109(17):63786381.

INGOLD, Tim. 2000. The perception of the environment: essays on livelihood, $d$ welling and skill. Londres: Routledge. - 2005. Evolution in four dimensions: genetic, epigenetic, behavioral, and symbolic variation in the history of life. Cambridge, Mass.: MIT Press.

JABLONKA, Eva; LAMB, Marion J. 2010. "The emergence of multispecies ethnography". Cultural Anthropology, 25(4): 545-576.

KIRKSEY, Eben S.; HELMREICH, Stefan. 2013. Making. Anthropology, archeology, art and architecture. Abingdon: Routledge.

KOHN, Eduardo. 2013. How forests think: toward an anthropology beyond the $\mathrm{hu}$ man. Berkeley, Los Angeles: University of California Press.

LANDECKER, Hannah. 2011. "Food as exposure: nutritional epigenetics and the new metabolism". Biosocieties, 6(2):167-194.

LEVI-STRAUSS, Claude; POUILLON, Jean. 1967. Race et histoire. Paris: Gonthier. MOSS, Lenny. 2003. What genes can't do. Cambridge, Mass.: MIT Press.

PITROU, Perig. 2014. "La vie, un objet pour l'anthropologie? Options méthodologiques et problèmes épistémologiques". L'Homme, 212:159-189.

- 2015. "Life as a process of making in the Mixe Highlands (Oaxaca, Mexico): towards a 'general pragmatics' of life". Journal of the Royal Anthropological Institute, 21(1):86-105.

PRAET, Istvan. 2013. Animism and the question of life. New York, Abingdon: Routledge 


\section{Resumo}

Como a Antropologia pode desenvolver suas próprias investigações além de natureza e de cultura? Junto com Latour ou Descola, Tim Ingold e Gisli Palsson lidam com esta questão, propondo quadros teóricos e metodologias específicos. O objetivo da revisão do livro editado por estes dois autores é mostrar que é possível fazer o estudo da vida, do ponto de vista antropológico, partindo de, pelo menos, duas premissas: a integração de dados biológicos na pesquisa etnográfica e a restituição de concepções de vida das sociedades não ocidentais. Exponho também alguns dos problemas epistemológicos que essas abordagens vêm levantando.

Palavras-chave Antropologia da vida, Processo vital, Epigenética, Biomedicina, Processo técnico.

\section{Abstract}

How can anthropology develop its own investigation beyond nature and culture? Along with Latour or Descola, Tim Ingold and Gisli Palsson are dealing with this issue, proposing specific theoretical frameworks and methodologies. The aim of this review is to show that, for anthropology, the study of life can be carried out from at least two standpoints: integrating biological data in ethnographical surveys or restituting conceptions of life in nonWestern societies. I also tackle some epistemological problems arising from theses approaches.

Key words Anthropology of life; Vital process; Epigenetic; Biomedicine; Technical process. 